\title{
Exposure assessment of nano-sized and respirable particles at different workplaces
}

\author{
Chuen-Jinn Tsai • Cheng-Yu Huang • Sheng-Chieh Chen • \\ Chi-En Ho • Cheng-Hsiung Huang • Chun-Wan Chen • \\ Cheng-Ping Chang $\cdot$ Su-Jung Tsai $\cdot$ Michael J. Ellenbecker
}

Received: 8 December 2010/Accepted: 27 March 2011/Published online: 12 April 2011

(C) Springer Science+Business Media B.V. 2011

\begin{abstract}
In this study, nanoparticle (NP, diameter $<100 \mathrm{~nm}$ ) and respirable particles measurements were conducted at three different nanopowder workplaces, including the mixing area of a nano- $\mathrm{SiO}_{2}$ epoxy molding compound plant (primary diameter: $15 \mathrm{~nm}$ ), bagging areas of a nano-carbon black (nanoCB) (primary diameter: $32 \mathrm{~nm}$ ) and a nano- $\mathrm{CaCO}_{3}$ (primary diameter: $94 \mathrm{~nm}$ ) manufacturing plant. Chemical analysis of respirable particle mass (RPM) and NPs was performed to quantify the content of manufactured nanoparticles in the collected samples. Nanopowder products obtained from the plants were used in the laboratory dustiness testing using a rotating drum tester to obtain particle
\end{abstract}

C.-J. Tsai $(\varangle)$ · C.-Y. Huang · S.-C. Chen · C.-E. Ho Institute of Environmental Engineering, National Chiao Tung University, 1001 University Rd., Hsinchu 30010, Taiwan

e-mail: cjtsai@mail.nctu.edu.tw

C.-H. Huang

Department of Environmental Engineering and Health, Yuanpei University, 306 Yuanpei St., Hsinchu 30010, Taiwan

C.-W. Chen - C.-P. Chang Institute of Occupational Safety and Health, Council of Labor Affairs, Executive Yuan, 99, Lane 407, Hengke Road, Shijr, Taipei 22143, Taiwan

\section{S.-J. Tsai · M. J. Ellenbecker}

University of Massachusetts Lowell,

One University Avenue, Lowell, MA 01854, USA mass and number distributions. The obtained laboratory data were then used to elucidate the field data. Both field and laboratory data showed that NP number and mass concentrations of manufactured materials were close to the background level. Number concentration was elevated only for particles with the electrical mobility diameter $>100 \mathrm{~nm}$ during bagging or feeding processes, unless there were combustionrelated incidental sources existed. Large fraction of nanomaterials was found in the RPM due to agglomeration of nanomaterials or attachment of nanomaterials to the larger particles. From this study, it is concluded that RPM concentration measurements are necessary for the exposure assessment of nanoparticles in workplaces.

Keywords Exposure assessment - Nanoparticle . Respirable particle - Dustiness testing .

Occupational environment

\section{Introduction}

The development and commercialization of nanotechnology are proceeding at an incredible pace. Many consumer products are being produced and more sophisticated products, processes and applications are being under development (NIOSH 2009; Tsai and Pui 2009; PEN 2010). The nanotechnology consumer products inventory contains more than 
1,000 products in health and fitness, home and garden, food and beverage, electronics and computers categories, etc. (PEN 2010). These products are very beneficial to our life yet the potential negative side effects of nanotechnology-related products are increasingly being questioned during production and handling of nanomaterials, and use and disposal of the products. In particular workers in workplaces may have the greatest potential to expose to nanoparticles (NPs) and lead to health risks (NIOSH 2009; Schulte et al. 2008; Tsai and Pui 2009).

Many toxicological studies have shown that NPs are more harmful to health than large particles because of their orders of magnitude higher particle number concentration and surface area than large particles of the same mass (NIOSH 2009). Therefore, it is very important to control NP exposure to prevent possible health effects, and exposure measurement is critical for assessing the health risks with the determined concentration levels as well as evaluating the control effectiveness. However, better exposure measurement methods are yet to be developed and there is a critical need to collect more exposure data at different workplaces.

Traditional exposure monitoring uses gravimetric technique when assessing airborne particle exposure, thus occupational thresholds for exposure are often based on mass concentrations. For example, NIOSH (2007, 2009) is about to propose 8-h TWA REL (tmie-weighted average, recommended exposure limit) for nano- $\mathrm{TiO}_{2}$ to be around $0.1 \mathrm{mg} / \mathrm{m}^{3}$. Scientific reviews found that bulk mass concentration is insufficient and suggest particle number and possibly surface area are better indicators (Aitken et al. 2004; Brouwer et al. 2004; Oberdöster et al. 2005). However, the actual exposure data are not enough to assess the risks of NP exposure in the workplace. Hence it is urgent to establish an appropriate sampling method and conduct exposure measurements at NP associated workplaces.

The National Institute for Occupational Safety and Health (NIOSH) proposed a novel nanoparticle emission assessment technique (NEAT) by using an optical particle counter (OPC, HHPC-6), a condensed particle counter (CPC, TSI 3007) and a filter-based sampler (Methner et al. 2010). These hand-held CPC and OPC are very convenient for field exposure measurement. Brouwer (2010) and Brouwer et al. (2009) reviewed many field exposure studies and concluded that although these studies contributed to a better understanding of the potential for exposure to MNOs (manufactured nano-objects), quantitative assessment of exposure MNOs was not possible. A more harmonized approach for analyzing and reporting of the results, such as the approach developed within the EU-sponsored project NANOSH, was recommended (Brouwer et al. 2009).

So far, few attempts have been made in establishing the practical relationship between measured dustiness and actual dust exposure at the workplace (Heitbrink et al. 1990; Brouwer et al. 2006). It would be very valuable to conduct the dustiness tests using actual nanopowders handled or produced in the workplaces, and relate the results to the field particle number and mass distributions. The rotating drum method is a frequently used method because of its ability to simulate a wide range of material handling processes for the estimation of dustiness (Mark 2005). Tsai et al. (2009) tested nano- $\mathrm{TiO}_{2}$ and fine $\mathrm{ZnO}$ using the EN15051 rotating drum with a modified sampling train where the respirable dust was characterized by a scanning mobility particle sizer (SMPS, Model 3936, TSI Inc., MN, USA), an aerodynamic particle sizer (APS, Model 3321, TSI Inc., MN, USA), and a micro-orifice uniform deposit impactor (MOUDI, Model 110, MSP Corp., St. Paul, USA). It was found that very few particles in mass below $100 \mathrm{~nm}$ were generated. The mass median aerodynamic diameters (MMADs) obtained by the MOUDI were 4.45 and $4.01 \mu \mathrm{m}$ for $\mathrm{TiO}_{2}$ and $\mathrm{ZnO}$, respectively.

This study aims at obtaining field exposure data in different nanomaterial handling or production workplaces. Measurement of nanoparticles dispersed from nanomaterial products obtained from the workplaces was conducted in the laboratory using a rotating drum dustiness tester. Measured particle concentrations and distributions in the workplaces were then discussed in light of the laboratory dustiness testing data.

\section{Materials and methods}

In this study, three different workplaces were selected, including the mixing area of an epoxy molding compound plant where nano- $\mathrm{SiO}_{2}$ powders (fumed silica, HDK N20, Wacker Chemie AG, Germany) were mixed with other materials, and the 
bagging areas of the nano-CB (product of a synthetic rubber company in Taiwan) and nano- $\mathrm{CaCO}_{3}$ (product of a plastic company in Taiwan) powders manufacturing plants. The primary particle diameter observed using a transmission electron microscope (TEM, JEOL JEM-2100F) is $15 \pm 2,32 \pm 7$, and $94 \pm 10 \mathrm{~nm}$ for nano-SiO${ }_{2}$, nano-CB and nano$\mathrm{CaCO}_{3}$, respectively (Table 1 ). The nanopowders were found to be loose agglomerates under the TEM. Particle number distributions were measured in real time while particle mass distributions, nanoparticle (NP) and respirable particle mass (RPM) concentrations were measured for 6-8 h per sampling day. The total number of manual samples in each workplace was three. After sampling, filter samples were analyzed for chemical species concentrations to determine the actual NP and RPM exposure concentrations of nanomaterials in these workplaces. This chemical analysis is critical since exposure measurements of NP are often interfered by background and incidental aerosols. Dustiness test was conducted using a rotating drum in the laboratory to compare the dustiness of the powders obtained from the plants. The results of the tests were then compared with the field exposure data for particle number and mass concentrations.

The floor plans of the three workplaces are shown schematically in Fig. 1, in which the workplaces are coded as Site A, B, and C for confidentiality.

\section{Sampling site}

The mixing area of the epoxy molding compound plant is coded as Site A, which is an enclosed space (dimensions: $14 \mathrm{~m}$ length $\times 7.4 \mathrm{~m}$ width $\times 4.2 \mathrm{~m}$ height) with limited general ventilation with only a small air conditioner (Fig. 1a). The main process was feeding raw materials such as coarse $\mathrm{SiO}_{2}$, fumed silica (nano- $\mathrm{SiO}_{2}$ ) and epoxy resin into a ball grinder below the floor. The feeding weight of coarse- $\mathrm{SiO}_{2}$, nano- $\mathrm{SiO}_{2}$ (HDK, N20) and resin per batch was 600 , 40 , and $120 \mathrm{~kg}$, respectively. In one working day of $8 \mathrm{~h}$, they were $2-5$ batches of feeding and mixing processes. There were several inlets for feeding the materials into the ball mill for mixing. Four inlets for coarse $\mathrm{SiO}_{2}$ were located about $8 \mathrm{~m}$ away from the control box of the ball grinder while an inlet for nano$\mathrm{SiO}_{2}$, resins and other additives was located next to the box. A large plastic tube (inner diameter $=13 \mathrm{~cm}$ ) with its open end positioned near the inlet for nano- $\mathrm{SiO}_{2}$ was connected to a small baghouse for reducing particle emissions. All raw materials used were delivered by an electrical forklift.

The bagging area of the nano-CB manufacturing plant is coded as Site B as shown in Fig. 1b. The bagging machines were equipped with local ventilation hoods and the bagging process continued throughout the day except during the lunch break. The bagging area was open to the ambient air and with very good ventilation. The weight per container bag was $600 \mathrm{~kg}$, and there were about 100 bags packed on each 8-h working day. The bags were transported by diesel forklifts to a storage area.

The bagging area of the calcium carbonate manufacturing plant is illustrated in Fig. 1c, which was located inside a large nanopowder plant with clean and enclosed production processes. The produced nano- $\mathrm{CaCO}_{3}$ powder was bagged by automatic

Table 1 Particle mass concentrations and distributions at different workplaces

\begin{tabular}{lccc}
\hline $\begin{array}{l}\text { Workplaces } \\
\text { Powder }\end{array}$ & $\begin{array}{l}\text { Site } \mathrm{A} \\
\text { Nano-SiO }\end{array}$ & $\begin{array}{l}\text { Site B } \\
\text { Nano-CB }\end{array}$ & $\begin{array}{l}\text { Site C } \\
\text { Nano-CaCO }\end{array}$ \\
\hline Primary diameter $(\mathrm{nm})$ & $15 \pm 2$ & $32 \pm 7$ & $94 \pm 10$ \\
Total mass conc. $\left(\mu \mathrm{g} / \mathrm{m}^{3}\right)$ & $4,653 \pm 376$ & $732 \pm 373$ & $510 \pm 112$ \\
RPM conc. $\left(\mu \mathrm{g} / \mathrm{m}^{3}\right)$ & $1,963 \pm 1,051$ & $159 \pm 52$ & $154 \pm 74$ \\
NP conc. $\left(\mu \mathrm{g} / \mathrm{m}^{3}\right)$ & $2.8 \pm 1.4$ & $10.0 \pm 3.4$ & $1.5 \pm 0.4$ \\
MMAD $(\mathrm{nm})$ & $4,611 \pm 1,671$ & $6,146 \pm 1,700$ & $5,232 \pm 1,767$ \\
GSD & $2.4 \pm 0.3$ & $2.3 \pm 0.2$ & $2.7 \pm 0.6$ \\
\hline
\end{tabular}

MMAD mass median aerodynamic diameter, GSD geometric standard deviation, Total mass conc. determined as the sum of concentrations of all stages of the MOUDIs, NP conc. nanoparticle mass concentration (aerodynamic diameter $<100 \mathrm{~nm}$ ) determined from the after filter of the MOUDIs with empty 10-th stage, RPM conc. respirable particle mass concentration determined by IOSH cyclones 


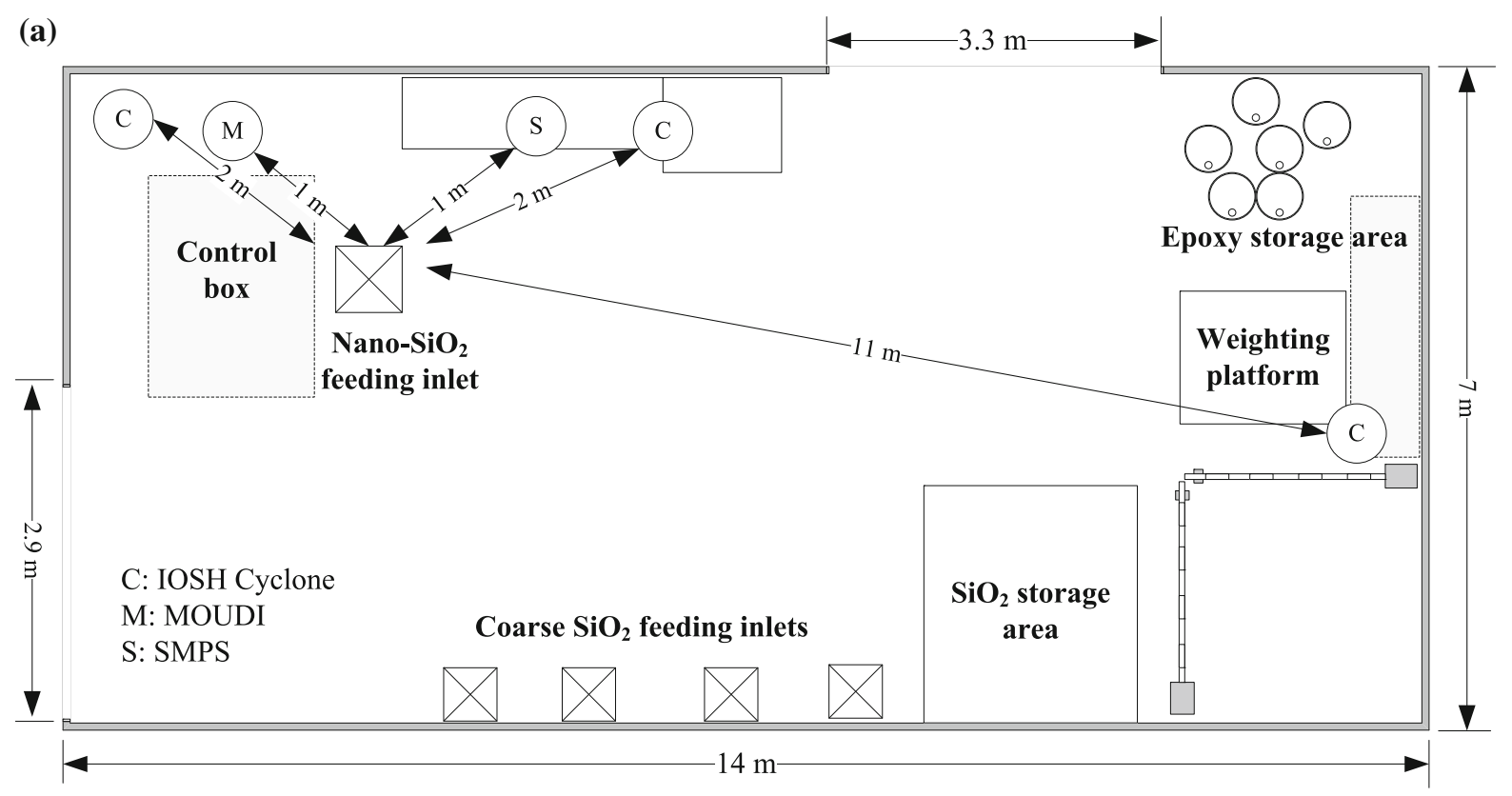

(b)

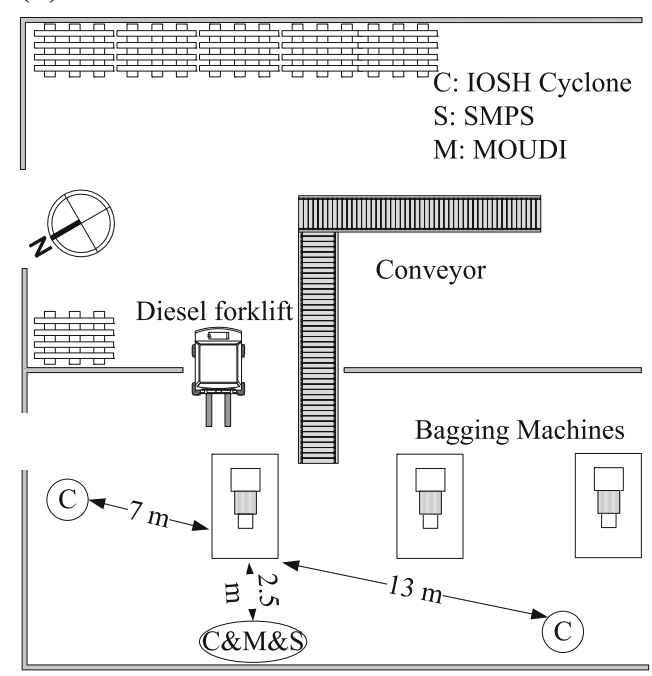

(c)

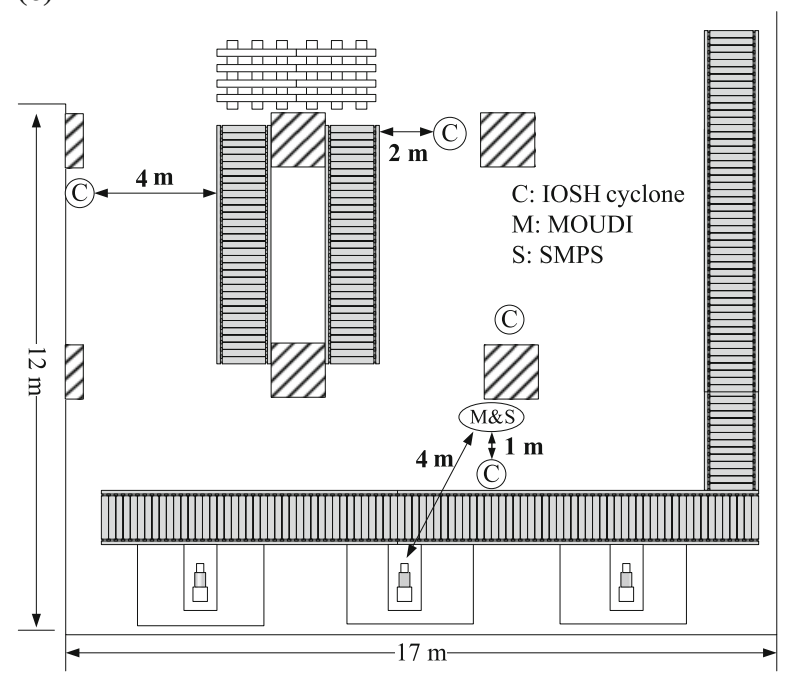

Fig. 1 Floor plan of the three workplaces a Site A, mixing area of the nano-SiO ${ }_{2}$-epoxy molding compound plant; $\mathbf{b}$ Site B, bagging area of the nano-CB manufacturing plant; c Site $\mathrm{C}$, bagging area of the nano- $\mathrm{CaCO}_{3}$ manufacturing plant

machines and the bags were transported by a conveyor to a storage area. Occasionally, diesel forklifts were used to move bags from the storage area to other areas. Bagging process continued throughout the 8-h working day except during the lunch break. The weight of each bag was $25 \mathrm{~kg}$ and there were about 900 bags produced during each day. A local ventilation hood was used to reduce particle emission near the outlet of each bagging machine.
General ventilation was not good since windows and doors at this area were closed during the bagging process.

Sampling and analytical methods

Each sampling was conducted for 6-8 h to measure particle number and mass concentrations simultaneously. Each workplace was tested for three times. 
The sampling devices included four pairs of IOSH cyclone (the Institute of Occupational Safety and Health, Taiwan) for RPM measurements, two MOUDIs (Model 110, MSP Corp., St. Paul, USA) for mass distribution and NP measurements and a SMPS (Model 3936, TSI Inc., MN, USA) for number distribution measurements. NP concentrations were obtained from the after filter while total particle mass concentrations were the sum of particle concentrations on all stages of the MOUDIs. The MOUDIs and SMPS were positioned as close to the particle emission source as possible to represent the worsecase scenario of NP exposure, while the cyclones were placed at different locations of the workplaces or outside of the workplace for background sampling.

Two MOUDIs were used for nanoparticle sampling. Silicone grease (KF-96-SP, Topco Technologies Corp., Taiwan) coated aluminum foils were used as the impaction substrates from the inlet to the 9th stages to reduce solid particle bounce, and the 10th stage was removed such that only NPs less than $100 \mathrm{~nm}$ were collected on the after filter. In one of the MOUDIs, Teflon filters (Zefluor P5PJ047, Pall Corp., New York, USA) were used as the after filter for gravimetric analysis and chemical analysis of $\mathrm{Si}$ content (Site A). Quartz filters (Tissuqartz 2500QATUP, Pall Corp., New York, USA) or mixed cellulose ester (MCE) filters (A500A047A, ADVANTEC MFC, Inc., Japan) were used in the after filter stage of the 2nd MOUDI for the chemical analysis of carbon (Site B) or element content (mainly $\mathrm{Ca}$, Site C), respectively.

Three to four pairs of IOSH cyclones (Tsai et al. $1999 \mathrm{a}, \mathrm{b})$ operated at $1.7 \mathrm{l} / \mathrm{min}$ were used at each workplace for area sampling of respirable particle mass (RPM). Similar to the MOUDIs, one of each pair of the IOSH cyclones was installed with Teflon filters for determining RPM and Si concentrations, while the other was installed with quartz or MCE filters for chemical analysis of carbon or element concentrations.

The SMPS system obtained particle number concentration at every $2 \mathrm{~min}$. The electric mobility diameter $\left(d_{\mathrm{m}}\right)$ of the SMPS ranged from 14 to $673 \mathrm{~nm}$ when the aerosol and sheath flow rates were set at 0.3 and $3 \mathrm{~L} / \mathrm{min}$, respectively.

Before and after sampling, the aluminum substrates and Teflon filters were conditioned at $22 \pm 1{ }^{\circ} \mathrm{C}$ and relative humidity of $40 \pm 5 \%$ for
$24 \mathrm{~h}$. A microbalance (Model CP2P-F, Sartorius, Germany) was used to determine particle mass. The samples collected by the MCE and Teflon filters were digested by a microwave digestion system (MARSXpress, CEM Corp., North Carolina, USA) before chemical analysis. For the digestion of nano- $\mathrm{SiO}_{2}$, $5 \mathrm{~mL}$ mixed acids of $\mathrm{HNO}_{3}+\mathrm{HClO}_{4}+\mathrm{HF}$ in the ratio of 3:5:2 (v/v) was used (Wang et al. 1997). Afterwards, MCE filters were analyzed using an inductively coupled plasma-optical emission spectrometer (ICP-OES, OPTIMA 2100 DV, PerkinElmer, Shelton, CT, USA) based on the NIOSH 7300 protocol (mainly $\mathrm{Ca}$ ). Teflon filters were analyzed by a UV-Vis spectrophotometer (Model U-3010, Hitachi, Japan) based on NIOSH 7601 protocol for silicon content. The recovery of $\mathrm{Ca}$ and silicon ranged from 94.2 to $103.1 \%$ and 91.2 to $101.5 \%$, respectively. The method detection limit determined in this study for $\mathrm{Ca}$ and $\mathrm{Si}$ was 0.0008 and $1.04 \mu \mathrm{g} /$ $\mathrm{m}^{3}$. In addition, quartz filter samples were analyzed by the thermal-optical reflectance (TOR) method for organic carbon (OC) and elemental carbon (EC) concentrations without gravimetric analysis. The quartz samples were stored in a $-18{ }^{\circ} \mathrm{C}$ freezer immediately after sampling. The detection limits for OC and EC determined in this study were 0.018 and $0.03 \mu \mathrm{g} / \mathrm{m}^{3}$, respectively (Chen et al. 2010; Zhu et al. 2010).

\section{Dustiness test}

Nano- $\mathrm{SiO}_{2}$, nano-CB, and nano- $\mathrm{CaCO}_{3}$ powders were tested for dustiness by using a rotation drum tester (Tsai et al., 2009). The test powders were dried in an oven controlled at $105{ }^{\circ} \mathrm{C}$ for $2 \mathrm{~h}$ prior to the tests.

The experimental setup is similar to that described in Tsai et al. (2009) as shown in Fig. 2a, except only two 20 ppi (pores per inch) porous foams was placed in the filter holder. Therefore, only particles smaller than the thoracic fraction were tested in the sampling train consisting of a MOUDI, an APS and a SMPS. The dispersed particles were sampled by the MOUDI for 2-min to determine mass distributions and monitored by the APS and SMPS for 30-min for number distributions. The tests were initiated until after the particle concentration was reduced below $10 \mathrm{\#} / \mathrm{cm}^{3}$ (SMPS) and $1 \# / \mathrm{cm}^{3}$ (APS). 
Fig. 2 Experimental setup of the rotating drum dustiness tester with a modified sampling train

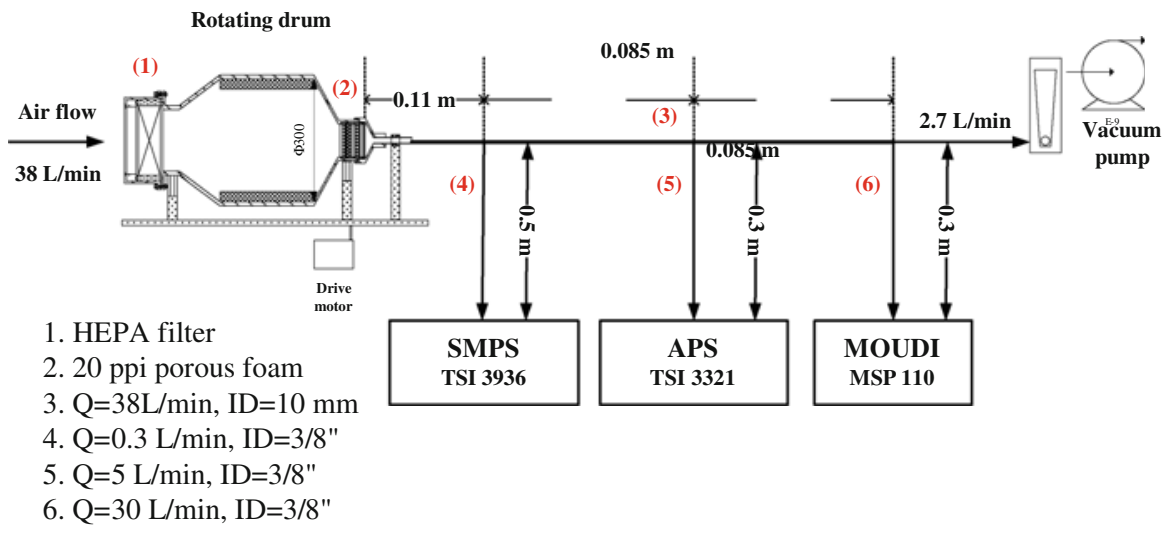

\section{Results and discussion}

RPM concentrations and mass distributions

Spatial average RPM concentrations determined by the IOSH cyclones at different workplaces are shown in Table 1 The highest concentration of 1,963 \pm $1,051 \mu \mathrm{g} / \mathrm{m}^{3}$ was observed at Site A, followed by Site $\mathrm{B}$ and Site $\mathrm{C}$, whose concentration was $159 \pm 52$ and $154 \pm 74 \mu \mathrm{g} / \mathrm{m}^{3}$, respectively. Site A was an enclosed space with limited general ventilation, whose RPM concentration was much higher than the background RPM concentration of $169 \pm 116 \mu \mathrm{g} / \mathrm{m}^{3}$ determined by IOSH cyclones. The open-ended plastic tube was also seemed to be ineffective to control particle emission during nano- $\mathrm{SiO}_{2}$ feeding process at Site A. In comparison, local ventilation hoods utilized near the bagging machines for reducing particle emission at Sites B and C were seemed to be effective, which led to much lower RPM concentrations. At Sites B and $\mathrm{C}$, the highest RPM concentrations were detected near the sources while lower RPM concentrations ranged from 77 to 125 and 87 to $129 \mu \mathrm{g} / \mathrm{m}^{3}$, respectively, were detected at other locations. The total particle mass concentrations at Site A-C determined by the MOUDIs near the sources are also shown in Table 1 to be $4,653 \pm 376,732 \pm 373$, and $510 \pm$ $112 \mu \mathrm{g} / \mathrm{m}^{3}$, respectively. These data indicate coarse particles greater than $4.0 \mu \mathrm{m}$ were also emitted in the workplaces than RPM.

The average mass distributions measured by the MOUDI near the sources of the workplaces are shown in Fig. 3. The MMADs of Site A-C were 4.6, 6.1 , and $5.2 \mu \mathrm{m}$ with the geometric standard deviations (GSDs) of 2.4, 2.3, and 2.7, respectively. These values are closed to those in Huang et al. (2010), who found that the MMAD of particles measured near the bagging machine of the fine $\mathrm{TiO}_{2}$ manufacturing plant was $5.89 \pm 1.04 \mu \mathrm{m}$ with the GSD of $2.43 \pm$ 0.48 , respectively. That is, airborne particles at theses nanopowder workplaces are super-micron rather than nano-sized in terms of mass concentration. This finding is also similar to a previous study which found that sharp peaks in the respirable and total mass concentration coincided with loading a hopper and replacing nanomaterials collection bags while very fine particle number had no apparent correlation to worker activities (Peters et al. 2009).

Nanoparticle mass concentrations and number distributions

Average NP mass concentrations measured by the after filter of the MOUDI with empty 10-th stage are

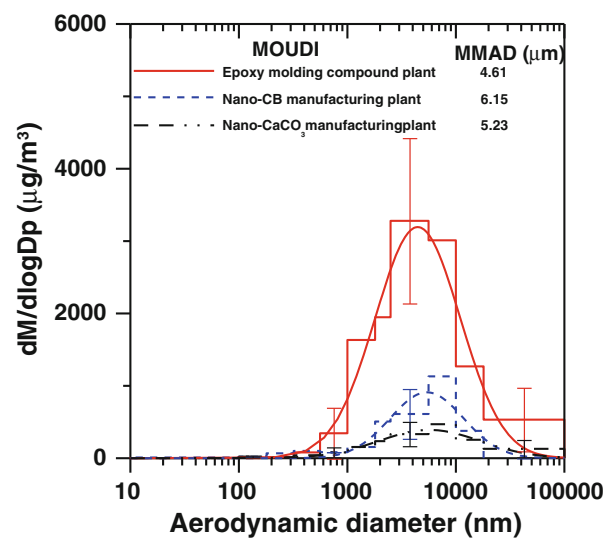

Fig. 3 Time-averaged particle mass distributions measured by the MOUDI at different workplaces 
shown in Table 1, which shows NP concentration at Site B averaged $10.0 \pm 3.4 \mu \mathrm{g} / \mathrm{m}^{3}$, followed by Site $\mathrm{A}$ and Site $\mathrm{C}$, whose average was $2.8 \pm 1.4$ and $1.5 \pm 0.4 \mu \mathrm{g} / \mathrm{m}^{3}$, respectively. Diesel forklifts were used at Site B very often to move large container bags to the storage area which led to higher NP concentration than Site A or Site C, where electrical forklifts were used or diesel forklifts were only used occasionally, respectively.

Total particle number concentrations $\left(d_{\mathrm{m}}\right.$ : $14-673 \mathrm{~nm}$ ) at each location varied considerably with sampling time as shown in Fig. 4. The background level seen at the lunch break or during non-activity period was typically about 3,700 (A2 at Site A), 4,000 (C2 at Site C) or $22,000 \# / \mathrm{cm}^{3}$ (B2 at Site B). In comparison, the concentration can peak at about

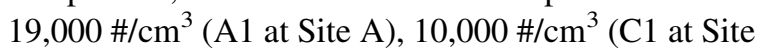
C, no diesel), $49,000 \# / \mathrm{cm}^{3}$ (C1' at Site C, with diesel forklifts), $180,000 \# / \mathrm{cm}^{3}$ (B1 at Site B). Particle number concentration was seen to be elevated during nanopowder loading or bagging process. Even much higher particle number concentration was observed at Site B or Site C when the diesel forklifts were used.

Particle number distributions are plotted in Fig. 5 in terms of activity. It is evident that the increase in particle number concentration during feeding or bagging event is due to particles greater than $100 \mathrm{~nm}$ in electric mobility diameter (A1, C1 in Figs. 4 and 5). Increase in nanoparticle concentration $\left(d_{\mathrm{m}}<100 \mathrm{~nm}\right)$ was not observed in Site A or C (without diesel forklift). However, when there is incidental sources of diesel soot present $\left(\mathrm{B} 1, \mathrm{Cl}^{\prime}\right.$ in Figs. 4 and 5), a sharp increase in nanoparticle number concentration will be observed with the mode diameter around $30 \mathrm{~nm}$. In case of Site B, the 2nd mode near $100 \mathrm{~nm}$ (B1 in Fig. 4) or $130 \mathrm{~nm}$ (B2 in Fig. 5) observed during bagging or lunch break, respectively, was due to agglomerated diesel soot particles instead of agglomerated nano-CB. This is because that the mode diameter of the latter is found to be greater than $300 \mathrm{~nm}$ in the rotating drum test, which is to be described later.

Similar results were also found in the measurement of bag filling activities of three CB plants in Kuhlbusch et al. (2004), where NPs detected in the bag filling area were mostly attributed to non-CB source such as forklift and gas heater emissions, and the forklift engine emitted ultrafine particles in the size range of $20-50 \mathrm{~nm}$.
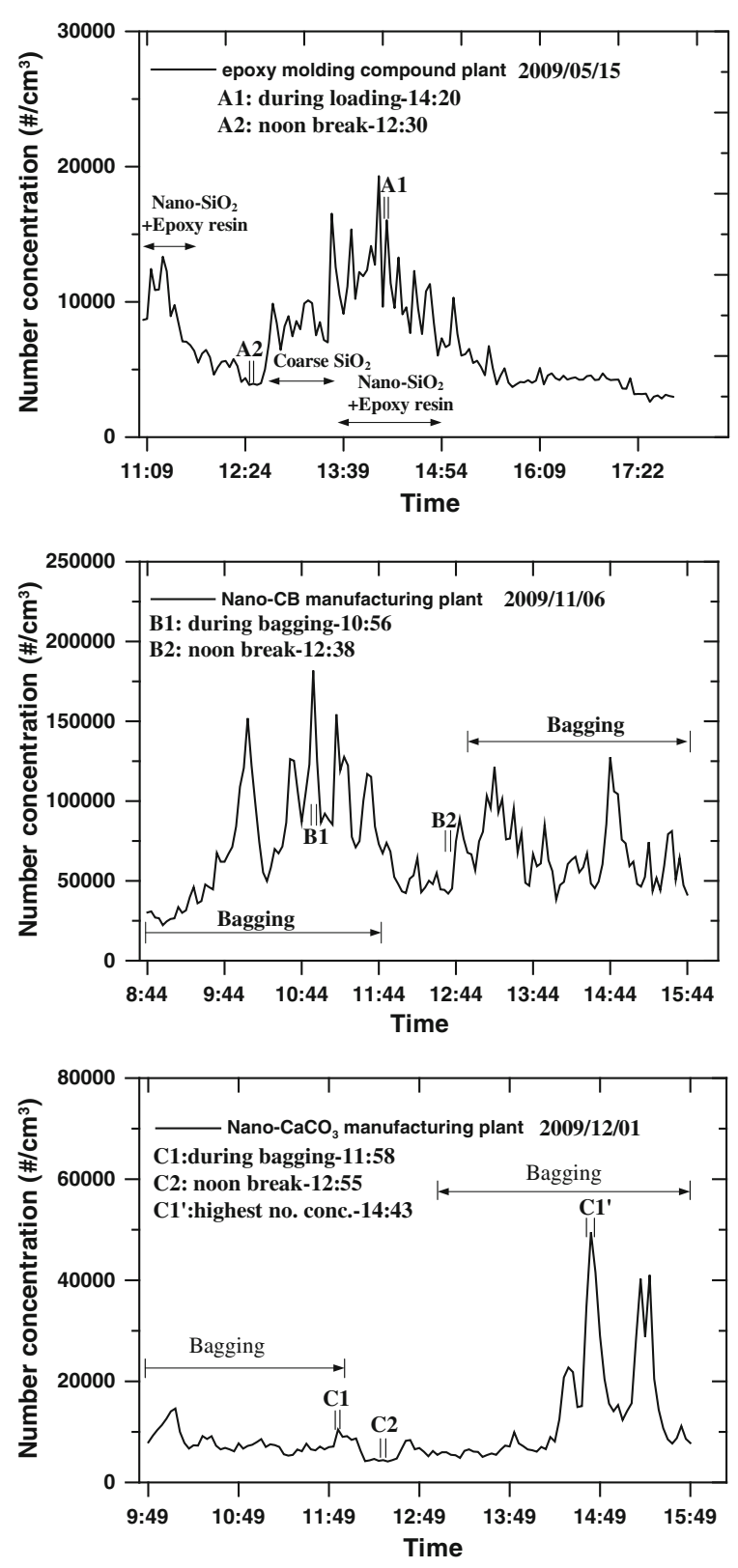

Fig. 4 Temporal particle number concentrations measured by the SMPS (electrical mobility diameter from 14 to $673 \mathrm{~nm}$ )

\section{Chemical compositions}

All sampled filters of the after-filter stage of the MOUDIs and IOSH cyclones were analyzed for chemical compositions except silicone grease coated aluminum foils of the MOUDIs. Results are shown in Table 2. At Site A, the average $\mathrm{SiO}_{2}$ concentrations in the RPM and NPs were $904 \pm 390 \mu \mathrm{g} / \mathrm{m}^{3}$ and 
Fig. 5 Particle number distributions at the workplaces, Site A-C. Highest number conc.-A1, $\mathrm{B} 1, \mathrm{C} 1$ (no diesel soot), $\mathrm{Cl}^{\prime}$ (with diesel soot). Lunch break-A2, B2, C2
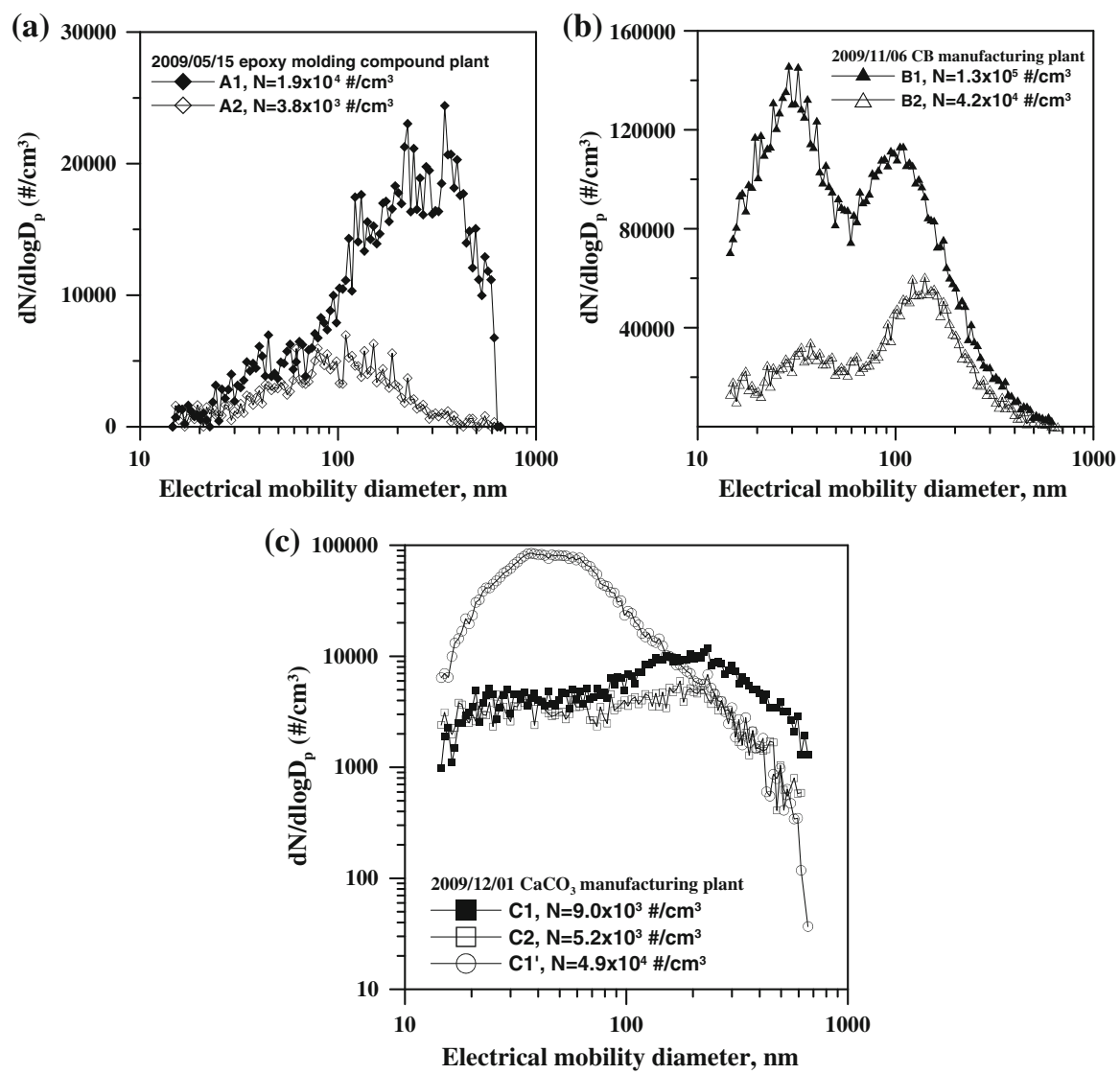

N.D. $\left(<2.23 \mu \mathrm{g} / \mathrm{m}^{3}\right)$, respectively. The mass ratio of $\mathrm{SiO}_{2}$ in the RPM was as high as $57 \%$ due to the agglomeration of nano- $\mathrm{SiO}_{2}$ during bagging activity. Almost no $\mathrm{SiO}_{2}$ content was found in nanoparticles, which is also confirmed from the number distribution data shown in Fig. 5a. At Site B, the concentration of $\mathrm{EC}$ and $\mathrm{OC}$ in NP were $4.3 \pm 1.9$ and $2.4 \pm 1.7 \mu \mathrm{g} /$ $\mathrm{m}^{3}$, respectively, accounting for 43 and $24 \%$ of NP mass. This high percentage was due to soot particles emitted from the diesel forklifts. The concentrations of EC and OC in RPM were $45.0 \pm 20.0$ and $39.1 \pm 15.8 \mu \mathrm{g} / \mathrm{m}^{3}$, respectively, each of them constituted approximately $25 \%$ in the RPM. At Site C, the average $\mathrm{CaCO}_{3}$ concentration in RPM was $66.9 \pm 44.9 \mu \mathrm{g} / \mathrm{m}^{3}$, accounting for $43 \%$ of RPM, while the $\mathrm{CaCO}_{3}$ content in the NPs was lower than the detection limit. This again indicates nano- $\mathrm{CaCO}_{3}$ agglomerated into larger particles during the bagging activity as shown in Fig. 5c.

These chemical analysis data provide further evidence that NP mass concentrations are low at nanopowder workplaces except when incidental sources exist such as diesel forklifts. Very large mass fraction of nanomaterials is detected as RPM. This further supports the suggestion made by Schneider

Table 2 Mass concentrations of constituents relevant to nanomaterials in NP and RPM at different workplaces

\begin{tabular}{|c|c|c|c|c|}
\hline & \multicolumn{4}{|c|}{ Unit: $\mu \mathrm{g} / \mathrm{m}^{3}$} \\
\hline & In NP & & In RPM & \\
\hline Site A & $\begin{array}{l}\mathrm{SiO}_{2} \\
\text { N.D. }\end{array}$ & & $\begin{array}{l}\mathrm{SiO}_{2} \\
904 \pm 390\end{array}$ & \\
\hline Site B & $\begin{array}{l}\mathrm{OC} \\
2.4 \pm 1.7\end{array}$ & $\begin{array}{l}\mathrm{EC} \\
4.3 \pm 1.9\end{array}$ & $\begin{array}{l}\text { OC } \\
39.1 \pm 15.8\end{array}$ & $\begin{array}{l}\text { EC } \\
45.0 \pm 20.0\end{array}$ \\
\hline Site C & $\begin{array}{l}\mathrm{CaCO}_{3} \\
\text { N.D. }\end{array}$ & & $\begin{array}{l}\mathrm{CaCO}_{3} \\
66.9 \pm 44.9\end{array}$ & \\
\hline
\end{tabular}

$N D$ not detectable

Method detection limit $(\mathrm{MDL})=2.23 \mu \mathrm{g} / \mathrm{m}^{3}$ for $\mathrm{SiO}_{2}$, $0.18 \mu \mathrm{g} / \mathrm{m}^{3}$ for OC, $0.03 \mu \mathrm{g} / \mathrm{m}^{3}$ for EC, and $0.002 \mu \mathrm{g} / \mathrm{m}^{3}$ for $\mathrm{CaCO}_{3}$ 
and Jensen (2009) that entire respirable size fraction should be assessed for risk from inhalation exposure to nanomaterials.

\section{Dustiness test}

The characteristics of test tested nanopowders are given in Table 3, including usage amount and apparent density. The apparent density is $0.04 \mathrm{~g} /$ $\mathrm{cm}^{3}$ for nano-SiO${ }_{2}, 0.310 \mathrm{~g} / \mathrm{cm}^{3}$ for nano-CB, and $0.464 \mathrm{~g} / \mathrm{cm}^{3}$ for nano- $\mathrm{CaCO}_{3}$, respectively, as determined according to the method described in CEN 15051 (CEN 2006).

During the 30-min test, 10 sets of 2-min SMPS and APS data, were obtained for each powder and the number distribution data for 2-min average and 30-min average are illustrated in Fig. 6. It can be seen that the number distribution functions for nano$\mathrm{SiO}_{2}$, nano-CB and nano- $\mathrm{CaCO}_{3}$ peak at 1954 , $3.4 \times 10^{4}$ and $2.7 \times 10^{4} \# / \mathrm{cm}^{3}$ for 2-min average, respectively, and the peak values are decreased to $1339,1.5 \times 10^{4}$ and $3169 \# / \mathrm{cm}^{3}$, respectively, for 30-min average for the SMPS data. For the APS data, the peak values of nano- $\mathrm{SiO}_{2}$, nano-CB and nano$\mathrm{CaCO}_{3}$ are decreased from 277, 2298, and $3120 \mathrm{\# /}$ $\mathrm{cm}^{3}$ at 2-min average to 253,1479 , and $372 \# / \mathrm{cm}^{3}$ for 30-min average. For clarity, the total particle concentrations measured by the SMPS versus time are plotted in Fig. 7. It shows an initially high but with ensuing sharp decrease in total particle concentration for nano- $\mathrm{CaCO}_{3}$ (from $14,800 \mathrm{\#} / \mathrm{cm}^{3}$ at 2 min to $56 \mathrm{\# l}$ $\mathrm{cm}^{3}$ at $30 \mathrm{~min}$ ), and nano-CB (from $19,200 \# / \mathrm{cm}^{3}$ at

Table 3 Comparison of MMAD and GSD between rotating drum dustiness tests and field exposure measurements

\begin{tabular}{llll}
\hline Powder & $\mathrm{Nano}_{-} \mathrm{SiO}_{2}$ & $\mathrm{Nano}-\mathrm{CB}$ & $\mathrm{Nano}-\mathrm{CaCO}_{3}$ \\
\hline $\begin{array}{l}\text { Apparent density } \\
\left(\mathrm{g} / \mathrm{cm}^{3}\right)\end{array}$ & 0.04 & 0.31 & 0.464 \\
Rotating drum & & & \\
$\quad$ Usage amount $(\mathrm{g})$ & 1.37 & 10.85 & 16.25 \\
MMAD $(\mu \mathrm{m})$ & $2.16^{\mathrm{a}} 9.32^{\mathrm{b}}$ & 7.53 & 7.02 \\
GSD & 2.312 .03 & 2.47 & 2.28 \\
Field & & & \\
MMAD $(\mu \mathrm{m})$ & 4.61 & 6.15 & 5.23 \\
GSD & 2.4 & 2.3 & 2.7 \\
\hline
\end{tabular}

Note: A single modal fit yields the MMAD of $5.49 \mu \mathrm{m}$ for Nano- $\mathrm{SiO}_{2}$

a 1 st mode, ${ }^{\mathrm{b}}$ 2nd mode
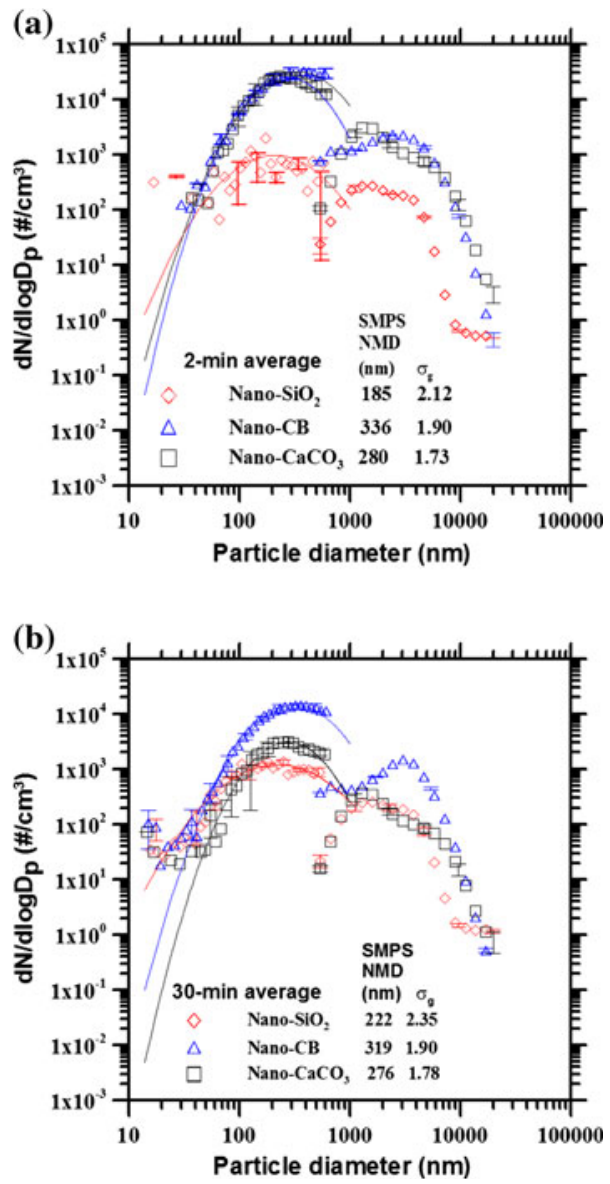

Fig. 6 Particle number distributions measured by the SMPS and the APS, rotating drum dustiness tester a 2-min average b 30-min average

2 min to $3,500 \# / \mathrm{cm}^{3}$ at $30 \mathrm{~min}$ ), while the concentration for nano- $\mathrm{SiO}_{2}$ remains low but increases steadily (from $740 \# / \mathrm{cm}^{3}$ at $2 \mathrm{~min}$ to $1,440 \# / \mathrm{cm}^{3}$ at $30 \mathrm{~min}$ ). Differences in the dust release rates were also observed for bentonite and organoclay powders (Jensen et al., 2009).

During the test, bimodal size distributions were found as shown in Fig. 6. Similar bimodal distributions were also reported during aerosolization of various nanopowders (Maynard et al. 2004; Schneider and Jensen 2008; Tsai et al. 2009). The shape of the distribution function for nano- $\mathrm{SiO}_{2}$ powder does not vary very much with the NMD (number median diameter) of $185 \mathrm{~nm}$ at 2-min changed to $222 \mathrm{~nm}$ at 30-min and the GSD of 2.12 at 2-min changed to 2.35 at 30-min for the SMPS data. The NMAD (number median aerodynamic diameter) is changed slightly 


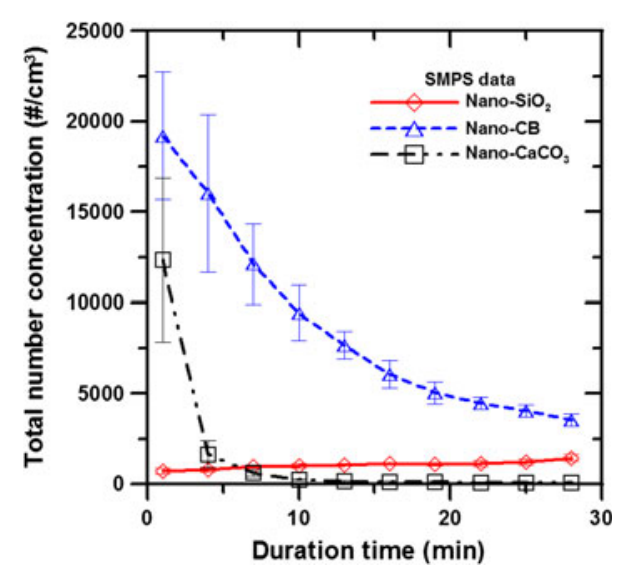

Fig. 7 Total particle number concentration versus time, rotating drum dustiness tester (electrical mobility diameter from 14 to $673 \mathrm{~nm}$ )

from 1,668 at 2 -min to $1,757 \mathrm{~nm}$ at 30 -min and the GSD of 1.84 at 2-min is changed to 1.86 at $30-\mathrm{min}$ for the APS data. For the other two powders, the distribution functions also do not alter very much, the NMDs of nano-CB and nano- $\mathrm{CaCO}_{3}$ are changed from 336 and $272 \mathrm{~nm}$ at 2-min to 319 and $276 \mathrm{~nm}$ at 30-min, respectively, and the GSDs are changed from 1.91 and 1.79 at $2-\min$ to 1.89 and 1.78 at $30-\mathrm{min}$, respectively, for the SMPS data. Similar trend of size distributions were also found in the APS data for nano-CB and nano- $\mathrm{CaCO}_{3}$. Comparing with the field number concentration distributions shown in Fig. 5, it can be concluded that the range of NMDs from 200 to $300 \mathrm{~nm}$ are similar for nano- $\mathrm{SiO}_{2}$ and nano- $\mathrm{CaCO}_{3}$. However, the NMD of the field data, about $100 \mathrm{~nm}$, is much smaller than the lab data (from 319 to $272 \mathrm{~nm}$ ) for nano-CB. This could be due to the agglomeration of diesel soot particles in the nano-CB workplace which dominated the workplace aerosols.

The 2-min average MOUDI mass distributions are shown in Fig. 8. It shows nano-CB had the highest dispersed concentration with the peak value of $8.7 \times 10^{4} \mu \mathrm{g} / \mathrm{m}^{3}$, followed by nano- $\mathrm{SiO}_{2}$ and nano$\mathrm{CaCO}_{3}$ with the peak value of $3.5 \times 10^{4}$ and $3.3 \times 10^{4} \mu \mathrm{g} / \mathrm{m}^{3}$, respectively. The MMADs of the nanoparticles dispersed by the rotating drum tester are shown in Table 3, which are 9.32 (2nd mode), 7.53 and $7.02 \mu \mathrm{m}$ for nano- $\mathrm{SiO}_{2}$, nano-CB and nano$\mathrm{CaCO}_{3}$, respectively. There is an additional mode with the MMAD of $2.16 \mu \mathrm{m}$ for nano- $\mathrm{SiO}_{2}$. If a single mode was assumed, then the MMAD was

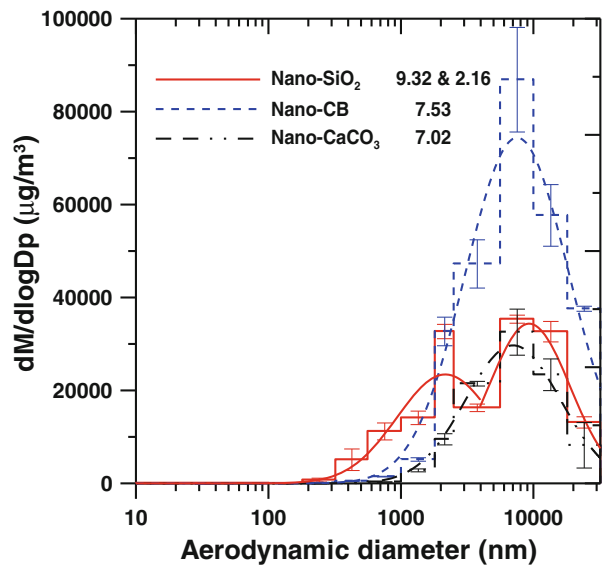

Fig. 8 Time-averaged particle mass distributions measured by the MOUDI, rotating drum dustiness tester

found to be $5.49 \mu \mathrm{m}$ for nano- $\mathrm{SiO}_{2}$, which is close to the average of the MMADs of the two modes, $5.59 \mu \mathrm{m}$. In comparison the field data showed the MMADs were 4.61, 6.15, and $5.23 \mu \mathrm{m}$, respectively, for Site A-C, which are slightly lower than those of the rotating drum results. The reason is because the distance between the field sampling location and the emission source is much longer than that between the sampler and the rotating drum in the laboratory dustiness test, which results in similar but slightly smaller MMADs in the field data.

Judging from both number and mass distributions obtained in the field and laboratory tests, it can be concluded that the rotating drum method generates particles with number and mass distributions similar to those observed in the field study. When there are combustion-related incidental sources which produce nano-sized and fine particles, number distribution measurements alone sometimes can't discern the manufactured nanoparticles from the background particles. However, mass distribution measurements often produce relevant data for manufactured nanoparticles with much less interference from combustion-related incidental sources.

\section{Conclusions}

More field data of nanoparticle exposure were obtained in this study for different nanopowder handling and bagging processes. Because of nanoparticle agglomeration which may lead to much 
larger particle diameter than the original primary diameter of nanomaterials, respirable cyclones (IOSH cyclones) and cascade impactors (MOUD) were used in the study in addition to the use of the real time instrument (SMPS). Samples collected by the manual devices were further analyzed to quantify the nanomaterial content in the NPs and RPM. A rotating drum dustiness tester was also used to obtain dispersed particle mass and number distributions using nanopowders produced from the plants. The test data were then used to elucidate the field data.

Both field and laboratory data showed that NP number and mass concentrations of manufactured nanomaterials were close to the background level. Number concentration was elevated only for particles greater than $100 \mathrm{~nm}$ in electrical mobility diameter during bagging or feeding processes. NP concentration was elevated substantially with a very small NMD of about $30 \mathrm{~nm}$ at the presence of diesel forklifts (in Site B, or occasionally in Site C). Chemical analysis of collected NP samples also showed negligible amount of manomaterials existed in the NP fraction.

The MMADs of the rotating drum testing was found to range from 5.49 to $7.02 \mu \mathrm{m}$, which is comparable but slightly larger than the field data of 4.61-6.15 $\mu \mathrm{m}$. Chemical analysis showed that high percentage of manomaterials indeed existed, which ranged from 43 to $57 \%$, in RPM due to the agglomeration of nanomaterials or the attachment of nanomaterials to coarse particles.

Therefore, it is suggested that both number and mass distributions of submicron $(<1 \mu \mathrm{m})$ and respirable particles be considered when assessing the exposure levels of nanopowder-related workplaces. By using real time instruments, number and mass distributions measured in proper size ranges should be able to reflect temporary variations due to nanopowder handing or processing activities. However, measurement of NP $(<100 \mathrm{~nm})$ concentration alone may not be adequate, as nanoparticle concentration may be elevated due to incidental sources, or perhaps low in both number and mass concentrations due to nanoparticle agglomeration or attachment to other coarse particles. It is concluded that RPM concentration measurements are necessary for the exposure assessment of nanoparticles in workplaces.

In the future, the test results of the rotating drum dustiness tester can be used to simulate particle number, surface area, and mass distributions observed in the nanopowder workplaces quantitatively, which are unsteady, spatially inhomogeneous and often influenced by background and incidental sources.

Acknowledgments The financial support from the Taiwan Institute of Occupational Health and Safety (contract number IOSH98-H324) and Taiwan Environmental Protection Agency (contract number EPA 99-U1U1-02-103) is gratefully acknowledged.

\section{References}

Aitken RJ, Creely KS, Tran CL (2004) Nanoparticles: an occupational hygiene review. Research report 274, Institute of Occupational Medicine (IOM). http://www.hse.gov.uk/ research/rrpdf/rr274.pdf. Accessed 10 December 2010

Brouwer DH (2010) Exposure to manufactured nanoparticle in different workplaces. Toxicology 269:120-127

Brouwer DH, Gijsbers JHJ, Lurvink MWM (2004) Personal exposure to ultrafine particles in the workplaces: exploring sampling techniques and strategies. Ann Occup Hyg 48:439-453

Brouwer DH, Links IH, de Vreede SA, Christopher Y (2006) Size selective dustiness and exposure; simulated woprkplace comparisons. Ann Occup Hyg 50:452-455

Brouwer DH, van Duuren-Stuurman B, Berges M, Jankowska E, Bard D, Mark D (2009) From workplace air measurement results toward estimates of exposure? Development of a strategy to assess exposure to manufactured nanoobjects. J Nanopart Res 11:1867-1881

CEN (European Committee for Standardization) (2006) Workplace atmospheres-Measurement of the dustiness of bulk materials-Requirements and test methods. CEN 15051

Chen SC, Tsai CJ, Huang CY, Chen HD, Chen SJ, Lin CC, Tsai JH, Chou CK, Lung SC, Huang WR, Roam GD, Wu WY, Dzumbova L (2010) Chemical mass closure and chemical characteristics of ambient ultrafine particles and other PM fractions. Aerosol Sci Technol 44:713-723

Heitbrink WA, Todd WF, Cooper TC, O'Brin DM (1990) The application of dustiness tests to the prediction of worker dust exposure. Am Ind Hyg Assoc J 51:217-223

Huang CH, Tai CY, Huang CY, Tsai CJ, Chen CW, Chang CP, Shim TS (2010) Measurements of respirable dust and nanoparticle concentrations in a titanium dioxide pigment production factory. J Environ Sci Health A 45:1227-1233

Jensen KA, Koponen IK, Clausen PA, Schneider T (2009) Dustiness behaviour of loose and compacted Bentonite and organoclay powders: what is the difference in exposure risk? J Nanopart Res 11:133-146

Kuhlbusch TAJ, Neumann S, Fissan H (2004) Number size distribution, mass concentration, and particle composition of $\mathrm{PM}_{1}, \mathrm{PM}_{2.5}$, and $\mathrm{PM}_{10}$ in bag filling areas of carbon black production. J Occup Environ Hyg 1:660-671

Mark D (2005) The use of reliable measurements of dustiness of chemicals in selecting the most appreciate dust control technology. IOHA, Pilanesberg, pp S2-S3 
Maynard AD, Baron PA, Foley M, Shvedova AA, Kisin ER, Castranova C (2004) Exposure to carbon nanotube material: aerosol release during handling of unrefined single-walled carbon nanotube material. J Toxicol Eviron Health A 67:97-107

Methner M, Hodson L, Geraci C (2010) Nanoparticle emission assessment technique (NEAT) for the identification and measurement of potential inhalation exposure to engineered nanomaterials-Part A. J Occup Eviron Hyg 7:127-132

NIOSH (2007) Draft current intelligence bulletin evaluation of health hazard and recommendations for occupational exposure to titanium dioxide. http://www.cdc.gov/niosh/ review/public/Tio2/default.html. Accessed 10 December 2010

NIOSH (2009) Approaches to safe nanotechnology: Managing the health and safety concerns associated with engineered nanomaterials. March 2009. (http://www.cdc.gov/niosh/ docs/2009-125/pdfs/2009-125.pdf. Accessed 10 December 2010

NIOSH Manual of Analytical Methods 7300, http://www. cdc.gov/niosh/docs/2003-154/pdfs/7300.pdf. Accessed 10 December 2010

NIOSH Manual of Analytical Methods 7601, http://www.cdc. gov/niosh/docs/2003-154/pdfs/7601.pdf. Accessed 10 December 2010

Oberdöster G, Oberdöster E, Oberdöster J (2005) Nanotoxicology: an emerging discipline evolving from studies of ultrafine particles. Eviron Health Perspect 113:823-839

PEN (2010) The Project on Emerging Nanotechnologies, http://www.nanotechproject.org/inventories/. Assessed 10 December 2010

Peters TM, Elzey S, Johnson R, Park H, Grassian V, Maher T, O’Shaughnessy P (2009) Airborne monitoring to distinguish engineered nanomaterials from incidental particles for environmental health and safety. J Occup Environ Hyg 6:73-81

Schneider T, Jensen KA (2008) Combined single-drop and rotating drum dustiness test of fine to nanosize powders using a small drum. Ann Occup Hyg 52(1):23-34

Schneider T, Jensen KA (2009) Relevance of aerosol dynamics and dustiness for personal exposure to manufactured nanoparticles. J Nanopart Res 11:1637-1650

Schulte P, Geraci C, Zumwalde R, Hoover M, Kuempel E (2008) Occupational risk management of engineered nanoparticles. J Occup Eviron Hyg 5:239-249

Tsai CJ, Pui DYH (2009) Recent advances and new challenges of occupational and environmental health of nanotechnology. J Nanopart Res 11(1):1-4

Tsai CJ, Shiau HG, Lin KC, Shih TS (1999a) Effect of deposited particles and particle charge on the penetration of small sampling cyclones. J Aerosol Sci 30(3):313-323

Tsai CJ, Shiau HG, Shih TS (1999b) Field study of the accuracy of two respirable sampling cyclones. Aerosol Sci Technol 31:463-472

Tsai CJ, Wu CH, Leu ML, Chen SC, Huang CY, Tsai PJ, Ko FH (2009) Dustiness test of nanopowders using a standard rotating drum with a modified sampling train. J Nanopart Res 11(1):121-131

Wang CF, Tu RH, Jeng SL (1997) Determination of silicon in airborne particulate matter by UV-visible spectrophotometry. Anal Chim Acta 342:239-245

Zhu CS, Chen CC, Cao JJ, Tsai CJ, Chou CK, Liu SC, Roam GD (2010) Characterization of carbon fractions for atmospheric fine particles and nanoparticles in a highway tunnel. Atmos Environ 44:2668-2673 